Ademar Fragoso Junior ${ }^{\mathrm{a}, \mathrm{c}}$

(iD) http://orcid.org/0000-0002-1946-5292

Eduardo Garcia Garcia ${ }^{\mathrm{b}, \mathrm{c}}$

(iD) https://orcid.org/0000-0002-4300-4314

a Ministério do Trabalho. Piracicaba, SP, Brasil.

b Fundação Jorge Duprat Figueiredo de Segurança e Medicina do Trabalho (Fundacentro). Centro Técnico Nacional. São Paulo, SP, Brasil.

${ }^{\mathrm{C}}$ Fundação Jorge Duprat Figueiredo de Segurança e Medicina do Trabalho (Fundacentro), Programa de Pós-Graduação Trabalho, Saúde e Ambiente. São Paulo, SP, Brasil.

Contato:

Ademar Fragoso Junior

E-mail:

ademarfjr@gmail.com

Artigo com base na dissertação intitulada "A atuação da fiscalização do trabalho no Brasil frente às peculiaridades da organização do transporte rodoviário de carga", de autoria de Ademar Fragoso Junior, apresentada ao Programa de Pós-Graduação Stricto Sensu Trabalho Saúde e Ambiente, da Fundacentro, São Paulo, em 2013.

Os autores informam que este trabalho não foi apresentado em reunião científica.

Os autores declaram que o estudo não foi subvencionado e que não há conflitos de interesses.

\section{Transporte rodoviário de carga: acidentes de trabalho fatais e fiscalização trabalhista}

\author{
Road freight transport: fatal work accidents and labor inspection
}

\section{Resumo}

Introdução: um grande número de acidentes de trabalho fatais (ATF) ocorre no Transporte Rodoviário de Cargas (TRC). Jornada de trabalho excessiva e descanso inadequado dos motoristas são apontados entre os principais fatores contribuintes. É atribuição do Ministério do Trabalho fiscalizar essas condições. Objetivos: avaliar se a ação da fiscalização do trabalho no setor de TRC recebeu atenção proporcional à magnitude dos indicadores de mortalidade por acidente de trabalho nessa atividade e analisar a inclusão dos fatores jornada e descanso nas inspeções. Métodos: estudo exploratório, quantitativo, descritivo, com base documental e bibliográfica e utilização de dados oficiais de ATF e da Fiscalização do Trabalho, de 2008 a 2012. Resultados: entre as 20 atividades/ocupações com mais mortes, o TRC (1430 óbitos; 37,97 mortes/100 mil vínculos) e a ocupação de motorista de caminhão de longas distâncias (1098 óbitos; 55,33 mortes/100 mil vínculos, em 2011) se destacaram. Contudo, as ações de fiscalização no setor representaram 1,4\% do total no período investigado e a inclusão da jornada e descanso dos motoristas se deu somente em metade dessas ações. Conclusão: é necessário incremento no número de fiscalizações no TRC e na abordagem dos fatores contribuintes para os ATF dos motoristas de caminhão.

Palavras-chave: acidentes de trabalho; fiscalização; transporte rodoviário de carga; motorista de caminhão; organização do trabalho.

\begin{abstract}
Introduction: a large number of fatal work accidents (FWA) occurs in road freight transport (RFT). Drivers' excessive working hours and inadequate rest are highlighted among the main contributing factors. In Brazil, the Ministry of Labor is the federal authority responsible for inspecting such working conditions. Objectives: to evaluate whether the labor inspection of the RFT sector received attention that was proportional to the magnitude of its fatal occupational injuries indicators and to analyze the verification of drivers' working and rest hours in the inspections. Methods: quantitative, descriptive and exploratory study using documentary and bibliographical information, and official data of FWA and Federal Labor Inspection from 2008 to 2012. Results: among the 20 activities/ occupations with more fatal accidents, the RFT (1430 deaths; 37.97 deaths/ 100,000 employed persons) and the long-distance truck driver occupation (1098 deaths; 55.33 deaths/100,000 employed persons, in 2011) were highlighted. However, the labor inspections carried out in the RTF sector represented $1.4 \%$ of the total number of the Federal Labor inspections, and the drivers' working and rest hours were checked only in half of these actions. Conclusion: it is necessary to increase the number of inspections in the RFT sector whilst the factors that contribute to truck drivers' FWA must be checked.
\end{abstract}

Keywords: occupational accidents; labor inspection; road freight transport; truck driver; work organization. 


\section{Introdução}

O transporte rodoviário é o principal meio de transporte de carga no Brasil. É responsável por cerca de $60 \%$ da carga transportada no país, utilizando uma malha rodoviária composta por aproximadamente 1,6 milhões de quilômetros e uma frota de 3 milhões de veículos de transporte de carga ${ }^{1}$. Em dezembro de 2012, estavam envolvidos na atividade cerca de 856 mil motoristas de caminhão ${ }^{2}$, formalmente declarados ao Ministério do Trabalho (MT). Neste número não estão computados os motoristas autônomos e os que trabalham sem registro. A Agência Nacional de Transportes Terrestres indica que há 790.000 autônomos no Registro Nacional de Transportadores Rodoviários de Cargas ${ }^{3}$.

Segundo dados do Instituto de Pesquisa Econômica Aplicada (IPEA) ${ }^{4}$, no ano de 2014 o custo total dos acidentes de trânsito nas rodovias federais, estaduais e municipais atingiu o valor aproximado de $\mathrm{R} \$ 40$ bilhões, com um custo médio de $\mathrm{R} \$ 647$ mil por acidente fatal. Entre esses acidentes estão os relacionados ao trabalho. Santana e colegas ${ }^{5}$ apontam que, embora o transporte rodoviário de cargas (TRC) seja um setor estratégico para o Brasil, apresenta diversos problemas estruturais, com alto custo social, incluindo alta mortalidade por Acidentes de Trabalho (AT) com motoristas de caminhões.

Estudos nacionais e estrangeiros apresentam a fadiga, sonolência, cansaço físico e mental, uso de drogas e pagamento por produção entre os principais fatores que levam a acidentes no trabalho com motoristas profissionais. Apesar disso, o TRC tem se organizado de forma a privilegiar a produtividade, geralmente atrelando a remuneração dos motoristas ao número e extensão das viagens, o que os leva a cumprir longas jornadas com pouco descanso, uma combinação considerada como um dos principais fatores que contribuem para a ocorrência de acidentes ${ }^{6-15}$.

O MT é responsável pela fiscalização dos aspectos trabalhistas, de segurança e saúde, nas atividades do país regidas por vínculos empregatícios. Como os recursos do poder público são limitados, e cada vez mais escassos, há necessidade de se definir critérios de priorização para o desenvolvimento de suas ações. Tendo em vista a relevância do setor de TRC para o país, o grande contingente de motoristas envolvidos e o elevado número de acidentes de trabalho fatais (ATF) que nele ocorrem, e considerando que jornada de trabalho e descanso estão entre os principais fatores que contribuem para a ocorrência de acidentes de trabalho de motoristas de caminhão de longas distâncias, questionou-se neste estudo se o setor tem recebido fiscalizações proporcionais à relevância dos seus indicadores de mortalidade por acidentes do trabalho.

Assim, os objetivos do estudo foram avaliar se a ação da fiscalização do trabalho no setor do TRC recebeu atenção proporcional à magnitude dos indicadores de mortalidade por acidente de trabalho dessa atividade e analisar a inclusão dos fatores "Jornada de trabalho" e "Descanso" dos motoristas nas inspeções avaliadas.

\section{Métodos}

Estudo exploratório, quantitativo e descritivo, com base documental e bibliográfica. A pesquisa teve como referência o período de 2008 a 2012.

Para identificar a relevância do TRC em relação à ocorrência de ATF, compararam-se os números absolutos e taxas de mortalidade de ATF, por atividade econômica e por ocupação, em relação às 20 atividades econômicas e às vinte ocupações com maior número de óbitos no período.

As quantidades de ATF por atividade econômica, segundo a Classificação Nacional de Atividades Econômicas (CNAE) ${ }^{16}$, foram obtidas do Anuário Estatístico de Acidentes do Trabalho (AEAT), publicado anualmente pelo Ministério da Previdência Social e pelo MT; utilizaram-se os AEAT dos anos $2010^{17}$ (contendo os dados de 2008 a 2010, inclusive) e $2013^{18}$ (com dados de 2011 e 2012).

As quantidades de ATF por ocupação, segundo a Classificação Brasileira de Ocupações $(\mathrm{CBO})^{19}$, foram fornecidas pelo Ministério da Previdência Social à Secretaria de Inspeção do Trabalho (SIT) do $\mathrm{MT}^{20,21}$, que as disponibilizou para este estudo. Foram utilizados os dados dos anos 2008, 2011 e 2012. Os relativos aos anos 2009 e 2010 não foram incluídos por inconsistência, por apresentarem dados muito díspares da média histórica para qualquer ocupação considerada e por falta de dados para diversas ocupações.

As taxas de mortalidade por atividade econômica foram obtidas, já calculadas, dos AEAT $2008^{22}$, $2010^{17}$ (o qual continha os dados de 2009 e 2010) e $2012^{23}$ (este, com os dados de 2011 e 2012). A taxa de mortalidade mede a relação entre o número total de óbitos decorrentes dos acidentes de trabalho verificados no ano e a população exposta ao risco de se acidentar nesse ano ${ }^{18}$.

Para a obtenção da taxa de mortalidade por ocupação (CBO), utilizou-se a mesma metodologia utilizada nos AEATs - considerou-se o número médio anual de vínculos para evitar imprecisão no cálculo, 
já que um trabalhador pode ter tido mais de um vínculo. Foi calculada pela expressão:

número de óbitos decorrentes de acidentes de trabalho (ATF) $\times 100.000$ número médio anual de vínculos

Os números médios anuais de vínculos de emprego foram obtidos da Relação Anual de Informações Sociais (RAIS). A RAIS consiste numa declaração obrigatória dos vínculos empregatícios feita anualmente por todos os empregadores, empresas individuais e todas as pessoas jurídicas de direito privado, ainda que não possuam empregados ${ }^{24}$.

Os dados sobre a fiscalização do trabalho foram disponibilizados para esta pesquisa pelo MT. Foram extraídos da base de dados denominada Sistema Federal de Inspeção do Trabalho (SFIT), na qual são inseridas as informações referentes às ações fiscais e às análises de AT realizadas pelos auditores-fiscais do trabalho ${ }^{25}$.

Os dados sobre as ações fiscais estavam agregados por CNAE e sem a identificação das empresas. Continham informações sobre a regularidade ou irregularidade dos aspectos trabalhistas (como o registro do empregado, salário, jornada de trabalho e descanso, entre outros) e de segurança e saúde do trabalho, referentes ao cumprimento das Normas Regulamentadoras (NRs) do Ministério do Trabalho ${ }^{26}$. Para este estudo foram analisadas as informações relativas aos atributos "Jornada de Trabalho" e "Descanso".

Com relação às análises de AT realizadas pelo MT, verificou-se o número de análises efetuadas por setor econômico (CNAE) no período do estudo. As análises de ATs são feitas pelos auditores-fiscais do trabalho em número bem menor do que as fiscalizações, geralmente relacionadas aos casos de ATF e contemplam um estudo detalhado do processo produtivo e do contexto em que ocorreu o AT investigado, com o fim de compreender os seus determinantes e promover a prevenção de ocorrências futuras $^{27}$. Também oferecem subsídio para o ajuizamento de ações regressivas do INSS contra empresas que deixaram de cumprir as NRs ou outras normas trabalhistas.

Para complementar a avaliação referente aos critérios de priorização de ações da Fiscalização do Trabalho, foi analisada a informação do MT a respeito da implantação de projetos específicos de fiscalização dirigidos ao TRC nos estados. Esses projetos foram concebidos conforme as diretrizes estabelecidas na Portaria 546/2010 ${ }^{25}$, que "disciplina a forma de atuação da Inspeção do Trabalho, a elaboração do planejamento da fiscalização, a avaliação de desempenho funcional dos Auditores Fiscais do Trabalho". A portaria determina que o planejamento e as metas da atuação fiscal devem definir focos em atividades econômicas ou temas a partir de diagnósticos fundamentados em análises de dados oficiais e seguir metas fixadas no Plano Plurianual (PPA) e nas orientações da Secretaria de Inspeção do Trabalho do MT.

\section{Resultados}

Segundo os dados dos Anuários Estatísticos de Acidentes de Trabalho (Tabela 1), no período de 2008 a 2012, entre as vinte atividades econômicas (CNAE) com maior número de ATF há distintas modalidades de transporte e de construção civil, seguidas por algumas de comércio. O TRC sobressai com o maior número de óbitos (1.430), representando $10,4 \%$ dos ATF do período. Com relação às taxas de mortalidade, o TRC aparece com a segunda taxa média no período (37,97 mortes/100 mil vínculos), atrás de "Extração de pedras, areia e argila" (40,23/100 mil vínculos) que, entretanto, apresenta o menor número absoluto de óbitos (115) entre essas vinte atividades.

Quanto aos ATF entre as 20 ocupações (CBO) com maior número de mortes por acidente de trabalho, considerando os anos 2008, 2011 e 2012 (Tabela 2), uma vez mais os dados das ocupações de motoristas e de trabalhadores de construção civil chamam atenção. Os motoristas de caminhão de longas distâncias (rotas regionais e internacionais) apresentam o maior número de óbitos nesses anos (1.098 no total), representando $17,2 \%$ do total, e a maior taxa de mortalidade em 2011 (55,33/100 mil vínculos). A ocupação de servente de obras mostra o segundo maior número de mortes (374) e a de montador de estruturas metálicas a segunda maior taxa de mortalidade (49,17/100 mil vínculos, em 2011). 


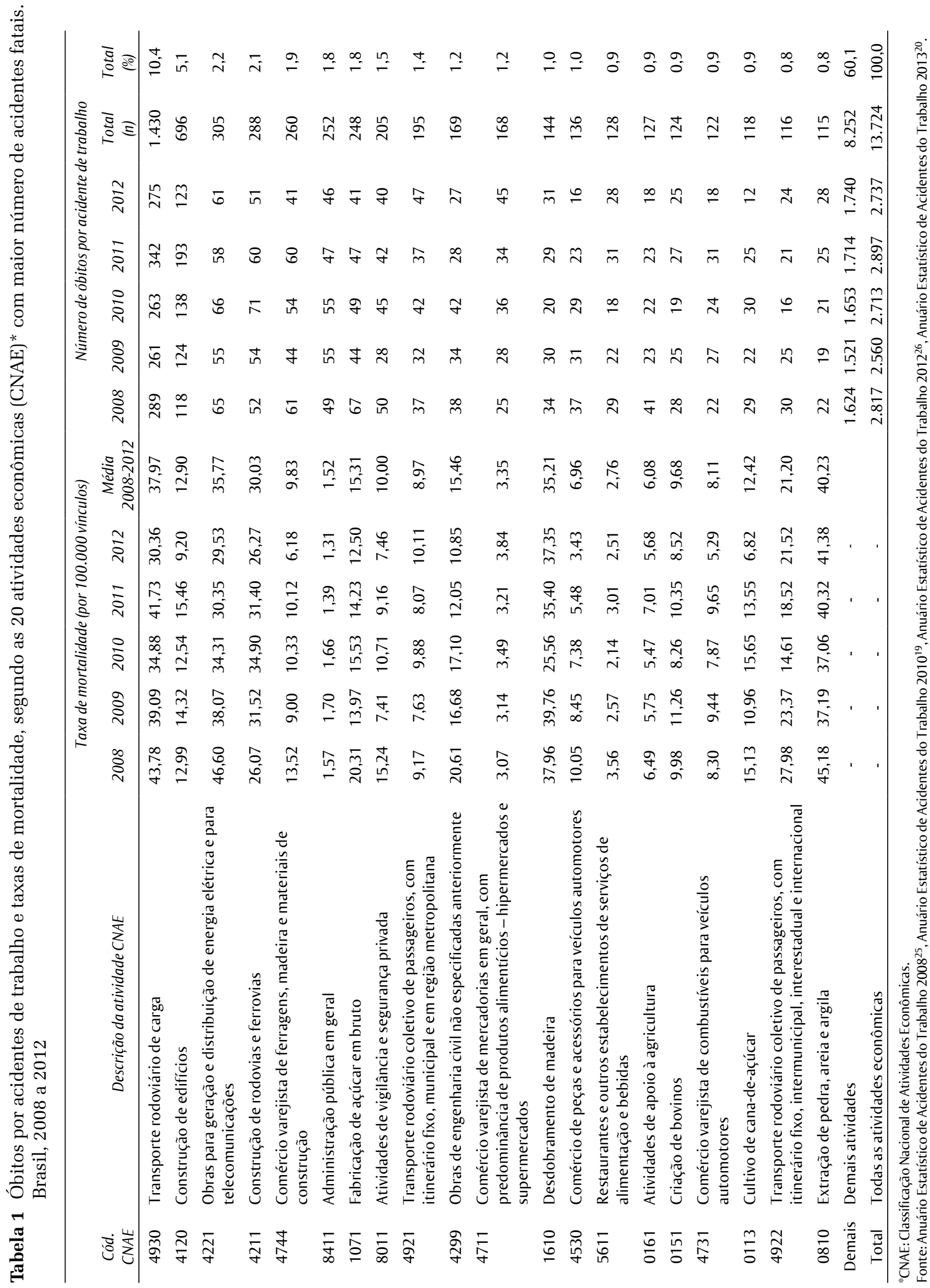


Tabela 2 Óbitos por acidentes de trabalho e taxas de mortalidade entre as 20 ocupações (CBO)* com maior número de acidentes fatais no Brasil, em 2008, 2011 e 2012**

\begin{tabular}{|c|c|c|c|c|c|c|c|c|c|}
\hline \multirow[b]{2}{*}{$C B O$} & \multirow[b]{2}{*}{ Descrição } & \multicolumn{3}{|c|}{$\begin{array}{l}\text { Taxa de mortalidade (por } \\
100.000 \text { vínculos) }\end{array}$} & \multicolumn{5}{|c|}{ Número de óbitos por acidente de trabalho } \\
\hline & & 2008 & 2011 & 2012 & 2008 & 2011 & 2012 & $\begin{array}{c}\text { Total } \\
\text { (n) }\end{array}$ & $\begin{array}{c}\text { Total } \\
(\%)\end{array}$ \\
\hline 782510 & $\begin{array}{l}\text { Motorista de caminhão (rotas } \\
\text { regionais e internacionais) }\end{array}$ & 41,19 & 55,33 & 46,01 & 262 & 442 & 394 & 1.098 & 17,2 \\
\hline 717020 & Servente de obras & 12,67 & 16,22 & 13,64 & 90 & 153 & 131 & 374 & 5,9 \\
\hline 784205 & Alimentador de linha de produção & 4,85 & 8,63 & 9,10 & 35 & 73 & 79 & 187 & 2,9 \\
\hline 517330 & Vigilante & 10,09 & 10,24 & 9,89 & 49 & 59 & 63 & 171 & 2,7 \\
\hline 715210 & Pedreiro & 10,78 & 13,57 & 13,96 & 35 & 64 & 69 & 168 & 2,6 \\
\hline 782310 & Motorista de furgão ou veículo similar & 16,55 & 19,81 & 15,06 & 29 & 44 & 36 & 109 & 1,7 \\
\hline 783225 & Ajudante de motorista & 13,67 & 19,90 & 9,84 & 29 & 50 & 26 & 105 & 1,6 \\
\hline 411005 & Auxiliar de escritório, em geral & 1,20 & 2,22 & 1,25 & 25 & 48 & 28 & 101 & 1,6 \\
\hline 715615 & Eletricista de instalações & 26,72 & 35,01 & 35,13 & 22 & 37 & 40 & 99 & 1,6 \\
\hline 521110 & Vendedor de comércio varejista & 1,72 & 1,63 & 1,57 & 30 & 33 & 33 & 96 & 1,5 \\
\hline 621005 & Trabalhador agropecuário em geral & 7,26 & 9,28 & 7,74 & 29 & 36 & 29 & 94 & 1,5 \\
\hline 911305 & $\begin{array}{l}\text { Mecânico de manutenção de } \\
\text { máquinas em geral }\end{array}$ & 10,09 & 14,96 & 19,83 & 17 & 28 & 39 & 84 & 1,3 \\
\hline 519110 & $\begin{array}{l}\text { Motociclista no transporte de } \\
\text { documentos e pequenos volumes }\end{array}$ & 24,91 & 25,48 & 20,90 & 24 & 30 & 26 & 80 & 1,3 \\
\hline 782405 & Motorista de ônibus rodoviário & 37,21 & 22,02 & 32,53 & 29 & 19 & 30 & 78 & 1,2 \\
\hline 517420 & Vigia & 4,95 & 7,76 & 7,35 & 16 & 27 & 25 & 68 & 1,1 \\
\hline 641015 & Tratorista agrícola & 20,90 & 14,77 & 15,34 & 23 & 19 & 21 & 63 & 1,0 \\
\hline 782410 & Motorista de ônibus urbano & 6,43 & 11,20 & 10,66 & 13 & 25 & 25 & 63 & 1,0 \\
\hline 622110 & $\begin{array}{l}\text { Trabalhador da cultura de cana-de- } \\
\text {-açúcar }\end{array}$ & 7,86 & 8,81 & 3,71 & 29 & 24 & 9 & 62 & 1,0 \\
\hline 724205 & Montador de estruturas metálicas & 36,25 & 49,17 & 24,93 & 17 & 29 & 16 & 62 & 1,0 \\
\hline \multirow[t]{2}{*}{724315} & Soldador & 9,72 & 13,03 & 10,76 & 15 & 24 & 21 & 60 & 0,9 \\
\hline & Demais ocupações & - & - & - & 959 & 1.144 & 1.053 & 3.156 & 49,5 \\
\hline Total & Todas as ocupações & - & - & - & 1.777 & 2.408 & 2.193 & 6.378 & 100,0 \\
\hline
\end{tabular}

As atividades econômicas (CNAE) que receberam maior número de ações fiscais efetuadas pelo MT são apresentadas na Tabela 3. Destacam-se atividades no setor de Serviços, sobretudo do Comércio Varejista como a atividade mais fiscalizada $(26,4 \%)$, e da construção de edifícios (9,3\%). Entre as nove atividades com maior número de fiscalizações, o TRC aparece como a menos fiscalizada, concentrando $1,4 \%$ das ações no período.

Entre os atributos que possuem registro no SFIT e que são checados pela Fiscalização do Trabalho durante as inspeções no TRC, encontram-se a "Jornada de Trabalho" e o "Descanso" dos motoristas. Os dados apresentados na Tabela 4 revelaram que esses atributos foram checados em cerca de metade das fiscalizações realizadas no setor e que, destas, próximo de $2 / 3$ foram consideradas regulares para o atributo "Jornada" e $3 / 4$ regulares para o atributo "Descanso", com pequenas variações entre 2008 e 2012.

Quanto ao quantitativo de Análises de AT realizadas pelo Ministério do Trabalho (Tabela 5), os dados do SFIT mostraram que, das nove atividades econômicas que concentraram um pouco mais de um quarto (26\%) das 9.513 análises realizadas no período, o setor de Construção de Edifícios se destacou com a maior proporção, $15,4 \%$ do total. As outras oito atividades 
tiveram número de análises variando de 1,2 a 1,7\% do total e incluíram, além de outras atividades econômicas relacionadas com a construção civil, atividades de serviços e de agroindústria. O setor de TRC teve o menor número de análises de AT no período, entre essas atividades, com 1,2\% do total.

Os dados do Ministério do Trabalho também mostraram que a atuação da fiscalização por meio de projetos específicos direcionados ao TRC foi iniciada a partir de 2010 em sete Unidades da Federação (Ceará,
Pernambuco, Piauí, Rio de Janeiro, Rondônia, Rio Grande do Sul e São Paulo), mas foi reduzida a quatro estados em 2011 (Espírito Santo, Goiás, Pernambuco e Rondônia) e em 2012 (Amazonas, Goiás, Rondônia e Rio Grande do Sul). Nos estados em que não havia um projeto específico para fiscalização do TRC, as fiscalizações no setor estavam incluídas em projetos denominados "Outras Demandas" ou "Demandas Residuais", juntamente com uma grande diversidade de outras CNAEs não consideradas prioritárias a ponto de demandarem um projeto específico.

Tabela 3 Quantidade de fiscalizações realizadas pelo Ministério do Trabalho, por atividade econômica, segundo a CNAE* Brasil, 2008-2012

\begin{tabular}{|c|c|c|c|c|c|c|c|}
\hline Atividade econômica & 2008 & 2009 & 2010 & 2011 & 2012 & $\begin{array}{c}\text { Total } \\
\text { (n) }\end{array}$ & $\begin{array}{c}\text { Total } \\
(\%)\end{array}$ \\
\hline 47 - Comércio varejista & 86.940 & 69.133 & 69.748 & 74.186 & 74.966 & 374.973 & 26,4 \\
\hline 41 - Construção de edifícios & 26.220 & 27.379 & 24.843 & 26.501 & 26.465 & 131.408 & 9,3 \\
\hline 56 - Alimentação & 15.359 & 11.554 & 12.961 & 14.253 & 14.336 & 68.463 & 4,8 \\
\hline $\begin{array}{l}45 \text { - Comércio e reparação de veículos } \\
\text { automotores e motocicletas }\end{array}$ & 11.144 & 8.806 & 9.325 & 12.322 & 12.449 & 54.046 & 3,8 \\
\hline 01 - Agricultura, pecuária e serviços relacionados & 9.514 & 11.971 & 10.599 & 10.710 & 11.200 & 53.994 & 3,8 \\
\hline $\begin{array}{l}46 \text { - Comércio para atacado, exceto veículos } \\
\text { automotores e motocicletas }\end{array}$ & 11.178 & 9.575 & 9.232 & 9.691 & 9.465 & 49.141 & 3,5 \\
\hline 86 - Atividades de atenção à saúde humana & 9.366 & 15.286 & 8.468 & 8.110 & 7.557 & 48.787 & 3,4 \\
\hline 43 - Serviços especializados para construção & 7.248 & 8.736 & 8.481 & 9.152 & 8.904 & 42.521 & 3,0 \\
\hline $\begin{array}{l}\text { 4930-2/02 - Transporte rodoviário de carga, exceto } \\
\text { produtos perigosos, intermunicipal etc. }\end{array}$ & 3.715 & 4.738 & 3.991 & 3.573 & 3.351 & 19.368 & 1,4 \\
\hline Demais atividades econômicas & 128.387 & 124.597 & 106.379 & 109.978 & 106.083 & 575.424 & 40,6 \\
\hline Total & 309.071 & 291.775 & 264.027 & 278.476 & 274.776 & 1.418 .125 & 100,0 \\
\hline
\end{tabular}

"CNAE: Classificação Nacional de Atividades Econômicas.

Fonte: Sistema Federal de Inspeção do Trabalho, Secretaria de Inspeção do Trabalho do Ministério do Trabalho ${ }^{16}$.

Tabela 4 Fiscalizações realizadas pelo Ministério do Trabalho, considerando os atributos Jornada e Descanso, na subclasse $\mathrm{CNAE}^{*}$ 4930-2/02 - Transporte rodoviário de carga intermunicipal, interestadual e internacional, Brasil, 2008-2012

\begin{tabular}{|c|c|c|c|c|c|c|c|c|c|}
\hline \multirow[b]{2}{*}{ Ano } & \multirow[b]{2}{*}{$\begin{array}{c}\text { Total de fiscalizações } \\
\text { na CNAE 4930-202 }\end{array}$} & \multicolumn{4}{|c|}{ Com fiscalização de Jornada } & \multicolumn{4}{|c|}{ Com fiscalização de descanso } \\
\hline & & $n$ & $\%$ & $\begin{array}{l}\text { Regular } \\
\text { (n) }\end{array}$ & $\begin{array}{c}\text { Regular } \\
(\%)\end{array}$ & $n$ & $\%$ & $\begin{array}{l}\text { Regular } \\
\text { (n) }\end{array}$ & $\begin{array}{c}\text { Regular } \\
(\%)\end{array}$ \\
\hline 2008 & 3.715 & 1.844 & 49,6 & 1.239 & 67,2 & 1.697 & 45,7 & 1.282 & 75,5 \\
\hline 2009 & 4.738 & 2.742 & 57,9 & 1.970 & 71,8 & 2.636 & 55,6 & 2.109 & 80,0 \\
\hline 2010 & 3.991 & 2.229 & 55,9 & 1.543 & 69,2 & 2.079 & 52,1 & 1.552 & 74,7 \\
\hline 2011 & 3.573 & 1.618 & 45,3 & 1.027 & 63,5 & 1.522 & 42,6 & 1.061 & 69,7 \\
\hline 2012 & 3.351 & 1.393 & 41,6 & 851 & 61,1 & 1.294 & 38,6 & 881 & 68,1 \\
\hline Total & 19.368 & 9.826 & 50,7 & 6.630 & 67,5 & 9.228 & 47,6 & 6.885 & 74,6 \\
\hline
\end{tabular}

*CNAE: Classificação Nacional de Atividades Econômicas.

Fonte: Sistema Federal de Inspeção do Trabalho, Secretaria de Inspeção do Trabalho do Ministério do Trabalho e Emprego ${ }^{16}$. 
Tabela 5 Análises de acidentes de trabalho realizadas pelo Ministério do Trabalho, Brasil, 2008-2012

\begin{tabular}{|c|c|c|c|}
\hline Atividade econômica & $\begin{array}{c}\text { Subclasse } \\
\text { CNAE }\end{array}$ & $\begin{array}{l}\text { Total } \\
\text { (n) }\end{array}$ & $\begin{array}{c}\text { Total } \\
(\%)\end{array}$ \\
\hline Construção de edifícios & $4120-4 / 00$ & 1.463 & 15,4 \\
\hline Comércio varejista com predominância de produtos alimentícios - supermercados & $4711-3 / 02$ & 161 & 1,7 \\
\hline Outras obras de engenharia civil não especificadas anteriormente & $4299-5 / 99$ & 134 & 1,4 \\
\hline Construção de rodovias e ferrovias & $4211-1 / 01$ & 131 & 1,4 \\
\hline Fabricação de açúcar em bruto & $1071-6 / 00$ & 129 & 1,4 \\
\hline Atividades de atendimento hospitalar, exceto pronto-socorro e urgências & $8610-1 / 01$ & 129 & 1,4 \\
\hline Frigorífico - abate de bovinos & $1011-2 / 01$ & 128 & 1,3 \\
\hline Cultivo de cana-de-açúcar & $0113-0 / 00$ & 112 & 1,2 \\
\hline Transporte rodoviário de carga, exceto produtos perigosos, intermunicipal etc. & $4930-2 / 02$ & 112 & 1,2 \\
\hline Demais atividades & - & 7.014 & 74,0 \\
\hline Total & - & 9.513 & 100,0 \\
\hline
\end{tabular}

Fonte: Sistema Federal de Inspeção do Trabalho, Secretaria de Inspeção do Trabalho do Ministério do Trabalho e Emprego ${ }^{16}$.

\section{Discussão}

Os dados analisados indicaram que, apesar de o TRC e o trabalho de motorista de transporte de cargas de longas distâncias se enquadrarem entre as atividades com os maiores indicadores de mortalidade por acidentes de trabalho no Brasil, o setor não foi adequadamente priorizado pela fiscalização do trabalho, no período do estudo. O baixo número de ações realizadas no setor e a pouca prioridade dada à fiscalização de atributos que contribuem para os acidentes, como a jornada de trabalho e o descanso do motorista, não encontra proporcionalidade com o alto número de ATF ocorridos no TRC entre 2008 e 2012.

O setor apresentou o maior número de ATF entre todas as atividades econômicas (CNAE) e a segunda maior taxa de mortalidade entre as 20 atividades com maior número de óbitos. Uma a cada dez mortes por acidente no trabalho no país, nesse período, ocorreu no TRC. Importante observar que o TRC superou a soma dos ATF e as taxas de mortalidade da segunda, terceira e quarta colocadas, que congregam três atividades econômicas importantes de construção civil: construção de edifícios; obras para geração e distribuição de energia e telecomunicações; e construção de rodovias e ferrovias. Ressalte-se que o setor de construção civil é considerado um dos mais perigosos em relação à ocorrência e à gravidade de acidentes de trabalho no Brasil ${ }^{28}$.

A mesma superioridade de indicadores de ATF do TRC em relação à construção civil e às demais atividades econômicas é observada quando se analisam os dados pela ótica da ocupação (CBO), que apontaram a de motorista de transporte de carga de longas distâncias com taxas de mortalidade anuais mais de três vezes maiores e com cerca do triplo do número absoluto de óbitos nos anos analisados, em relação à segunda ocupação com maiores indicadores, a de servente de obras. Segundo Fragoso ${ }^{29}$, a ocupação de motorista de caminhão de rotas regionais e internacionais contribuiu com 17,5\% do total de mortes por AT entre 2005 e 2008 e 18,2\% do total no período 2011-2012.

Santana e colegas $^{5}$, em estudo realizado com dados do Sistema de Informação sobre Mortalidade (SIM) abrangendo os anos de 2006 a 2010, identificaram números de magnitudes semelhantes aos deste estudo: 1.593 óbitos por acidente de trabalho (AT) com motoristas do setor, no período, com um coeficiente de mortalidade por AT variando de 49,6 (em 2006) a 44,6/100.000 (em 2010). Apesar dessa diminuição no total dos indicadores no país, os autores verificaram um aumento do coeficiente nas regiões Norte, Centro-Oeste e Nordeste nesse período e uma tendência de elevação entre 2009 e 2010 no Brasil como um todo. Embora efetuado a partir de uma fonte diferente de registros, esses dados corroboram os encontrados neste estudo.

Apesar da gravidade mostrada pelos indicadores de ATF no TRC, os dados do Ministério do Trabalho indicam que, entre as nove atividades econômicas (CNAE) que receberam mais fiscalizações ao longo dos cinco anos avaliados, congregando cerca de $60 \%$ do total das ações, mais da metade delas, 33,7\%, foram concentradas em atividades de comércio 
(Varejista; Veículos; Atacado) e 12,3\% se deram na construção civil (Edifícios; Serviços Especializados para Construção). Apenas 1,4\% das ações fiscais do MT foram dirigidas ao TRC. Mesmo com a constância da magnitude dos indicadores ao longo do período de referência deste estudo, praticamente não houve variação nos números e nas proporções das fiscalizações realizadas entre essas atividades.

Além disso. os dados do Ministério do Trabalho analisados neste estudo também indicaram que os atributos "Jornada" e "Descanso", que deveriam ser rotineiramente avaliados, foram verificados apenas em cerca de metade das inspeções e, quando fiscalizados, foram concluídos como regulares na maioria dessas fiscalizações, o que não parece condizer com o modo predominante de pagamento por produção, que induz longas jornadas com pouco descanso, nem com a elevada mortalidade por acidentes no setor.

Dentre os fatores contribuintes aos acidentes com caminhões, a fadiga e a sonolência são apresentados, tanto pela literatura científica internacional como nacional, como fatores preponderantes na causalidade de acidentes. Para especialistas ${ }^{6}$, embora não haja uma definição estabelecida do que seja a fadiga humana, definições gerais contemplam tanto fatores físicos como mentais. O termo é utilizado para descrever desde um desconforto por excessiva demanda de um grupo de músculos, até a redução ou perda da capacidade física e/ou cognitiva como resultado de cansaço físico ou mental, podendo afetar habilidades como força, velocidade e tempo de reação, coordenação, equilíbrio e tomada de decisões. A fadiga também é descrita como consequência de baixa qualidade e de pouca quantidade de sono restaurador, assim como da perda progressiva do estado de alerta, resultando em sono e dificuldade em permanecer acordado, dificuldade de concentração e de avaliar sinais potencialmente importantes. Praticamente, todos esses fatores se aplicam ao trabalho de motoristas de longas distâncias, sobretudo os que apontam a fadiga como resultado do tempo excessivo de envolvimento continuado no trabalho (jornada) associado ao descanso inadequado, levando ao comprometimento físico e mental. Esses fatores estão relacionados à organização do trabalho nessa atividade ${ }^{6}$.

Estudos mostram que quanto maior o tempo de direção, maior o risco de acidentes. Goudswaard et al. ${ }^{8}$ verificaram que após 4 horas contínuas de direção o risco de acidentes é dobrado e após 8 horas chega a ser até dez vezes maior, e concluíram que a fadiga e a sonolência são fatores contribuintes em $15 \%$ a $20 \%$ dos acidentes com caminhões. Segundo o Conselho Europeu de Segurança nos Transportes ${ }^{9}$, pesquisas conduzidas em alguns países membros da União Europeia indicaram que a fadiga foi um fator significante em $20 \%$ dos acidentes rodoviários de transporte comerciais nos países participantes das pesquisas.

Beaulieu $^{10}$ afirma que dormir ao volante como consequência da fadiga é uma das maiores questões relacionadas à segurança no transporte rodoviário. Segundo o autor, nos Estados Unidos atribui-se à fadiga aproximadamente 100.000 acidentes de veículos pesados e 1.500 mortes por ano, sendo esse fator estimado como causa em $30 \%$ a $40 \%$ dos acidentes com caminhões e em 15\% dos acidentes fatais envolvendo esses veículos. Ainda segundo o autor, naquele país o custo dos acidentes relacionados à fadiga é estimado em cinco bilhões de dólares anuais.

Arnedt et al. ${ }^{11}$, assim como Lamond e Dawson ${ }^{12}$, conduziram estudos que mostraram que a queda de desempenho na execução de atividades como dirigir 17-19 horas e 20-25 horas sem dormir é similar a dirigir com concentração de álcool no sangue de $0,05 \%$ e $0,10 \%(0,10$ gramas de etanol por $100 \mathrm{ml}$ de sangue), respectivamente. Segundo o International Center for Alcohol Policies ${ }^{30}$, a concentração de $0,10 \%$, é o dobro do limite legal da maioria dos países. No Brasil, nenhuma quantidade de álcool é permitida, conforme o Art. 276 do Código de Trânsito Brasileiro ${ }^{31}$.

Moreno e Rotenberg ${ }^{7}$ identificaram que motoristas que fazem longas viagens no Brasil chegam a dirigir 14 horas por dia. Ulhôa e colegas ${ }^{13}$ encontraram que $28,1 \%$ dos motoristas de caminhão entrevistados em sua pesquisa trabalhavam mais de dez horas por dia e notaram que as longas jornadas de trabalho e horários irregulares a que estavam submetidos comprometiam o sono desses trabalhadores e aumentavam o risco de acidentes. Em pesquisa de Pinho e colegas ${ }^{14}$ encontrou-se que a causa predominante de acidentes em trabalho envolvendo 300 motoristas foi a sonolência, declarada por $26,5 \%$ deles.

Silva ${ }^{15}$ indica que dentre os fatores relacionados ao envolvimento de motoristas de caminhão em acidentes de trabalho estão o uso de drogas, o cansaço físico e mental e o pagamento por comissão. Segundo Moreno e Rotenberg ${ }^{7}$, o pagamento por comissão em função da produção faz parte do modelo que impera no setor, e observam que a direção por longos períodos é uma condição imposta aos motoristas por este modelo. A condição ainda se agrava porque os motoristas que fazem longas viagens trabalham sob a pressão dos horários de entrega, o que os leva ao consumo de substâncias estimulantes para se manterem acordados. Silva ${ }^{15}$ também nota que os trabalhadores, especialmente os autônomos, têm sua renda atrelada diretamente às viagens que realizam e que os motoristas contratados, isto é, empregados da empresa, são remunerados com um salário fixo mais uma comissão que é proporcional à quilometragem rodada. 
Beaulieu $^{10}$ aponta dois aspectos importantes a serem considerados para a prevenção de acidentes no setor do TRC: a regulação e a fiscalização. De acordo com Fragoso ${ }^{29}$, em relação às regras da União Europeia, Austrália e Estados Unidos, a legislação brasileira é bem mais permissiva quanto aos tempos de trabalho dos motoristas. O autor detalha os tempos de direção e descanso permitidos nessas localidades. O mais restritivo é a União Europeia, cujo regulamento expressa o objetivo de melhorar a segurança nas estradas e garantir aos motoristas boas condições de trabalho. Define que se pode dirigir 9 horas por dia, sendo 4,5 horas contínuas, com intervalo para descanso de 45 minutos. Permite-se estender até 10 horas duas vezes na semana, com intervalo mínimo de 11 horas para repouso diário. O motorista pode dirigir por até 56 horas semanais, mas não exceder 90 horas em duas semanas consecutivas, observando um descanso semanal mínimo de 45 horas.

No Brasil, até 2012 não havia uma lei específica sobre o exercício da profissão de motorista. A Lei $12.619 / 2012^{32}$ regulou a atividade dos motoristas, incluindo a obrigatoriedade do controle de jornada. A lei superveniente, Lei 13.103/2015 ${ }^{33}$, em vigor, alterou diversas disposições, mantendo essa obrigatoriedade. No entanto, mostrou-se mais permissiva quanto à jornada. O tempo máximo de direção contínua previsto na legislação é de 5,5 horas, com 30 minutos de descanso e tempo diário de 8 a 12 horas (se previsto em convenção ou acordo coletivo). Não se computa como jornada quaisquer tempos em que o motorista não esteja dirigindo (refeição, repouso, descanso e espera). O intervalo de repouso diário é de 11 horas, podendo ser fracionado com uma parcela mínima de 8 horas contínuas. Os períodos de parada obrigatória podem ser contados como parte dessas 11 horas. O descanso semanal é de 35 horas e não há previsão na lei para o tempo máximo de direção semanal. A lei ainda estabelece que, "salvo previsão contratual, a jornada do motorista empregado não tem horário fixo de início, de final ou de intervalos”. Isso dificulta a fiscalização trabalhista no que concerne à checagem do cumprimento das jornadas.

Nesse sentido, uma hipótese, que merece maior investigação para explicar a avaliação de grande número de atributos de "Jornada de trabalho" e de "Descanso" como "Regulares" pela fiscalização do trabalho, é de que os motoristas não são encontrados com frequência nos estabelecimentos das transportadoras, passando a maior parte de seu tempo nas estradas. Sem o contato com a pessoa do motorista e não havendo meios de confrontação com os controles de jornada mantidos pelas empresas, quando estes são feitos, conclui-se pela regularidade. Se isto viesse a se confirmar, seria necessário discutir estratégias de atuação fiscal que permitissem contornar esse problema.
Segundo Beaulieu ${ }^{10}$, embora muitos países tenham regras adequadas sobre o tempo de direção e os períodos de descanso dos motoristas, a fiscalização é fraca. $\mathrm{O}$ autor considera essa questão muito grave, já que as regras sobre as horas do motorista, incluindo períodos de descanso, são frequentemente ignoradas e assevera que é reconhecido que uma fiscalização forte pode ajudar a reduzir acidentes.

Piore e Schrank ${ }^{34}$ consideram que a característica do modelo de inspeção trabalhista nos Estados Unidos é contenciosa, ou repressiva, por natureza, em contraposição ao modelo latino-americano, que é pedagógico, onde os inspetores do trabalho agem através do aconselhamento e da persuasão e, apenas ocasionalmente, utilizam-se da coerção para fazerem as empresas se adequarem às leis. Eles argumentam que os inspetores norte-americanos buscam o respeito às leis no longo prazo através de punições, enquanto os latino-americanos tratam as transgressões como produto da ignorância, ineficiência e "pobreza" dos empregadores. Segundo Cardoso e Lage ${ }^{35}$, o Brasil é um país que pode ser enquadrado entre aqueles que possuem um "sistema muito detalhado e rígido em termos formais, mas muito flexível na prática”.

Neste estudo, observou-se, também, um grande descompasso entre o número de acidentes no setor e o número de acidentes de trabalho nele analisados. Apenas 1,2\% das análises realizadas pela fiscalização foram dirigidas ao TRC, bem menos do que na construção civil, que recebeu a maior proporção das análises $(15,4 \%)$, quase treze vezes maior do que a do setor de TRC. Isso chama a atenção quando se leva em consideração que a análise de acidentes de trabalho está entre as atribuições dos auditores para compreender as causas contribuintes dos acidentes e para municiar o Ministério da Previdência Social com informações para o ingresso de ações regressivas contra os empregadores, objetivando o ressarcimento dos custos e danos provocados pelos acidentes, como previsto no Art. 341 do Decreto 3.048/1999 ${ }^{20}$.

Embora não se busque neste trabalho a explicação para o baixo número de análises de acidentes no setor, uma hipótese a ser investigada é a de que acidentes rodoviários raramente são percebidos como acidentes de trabalho, mas sim como acidentes de trânsito. O que dá início a uma investigação de acidente de trabalho geralmente é um comunicado da própria empresa ao órgão local do Ministério do Trabalho, a denúncia feita por algum sindicato ou trabalhador e até mesmo notícias veiculadas na imprensa. Os acidentes ocorridos na construção civil têm sido percebidos como acidentes de trabalho e, como tal, repercutem na mídia, o que não ocorre no setor de transporte rodoviário.

Os critérios que foram utilizados pelo planejamento da Fiscalização do Trabalho e consequente 
priorização das atividades econômicas fiscalizadas no período analisado não puderam ser identificados. Contudo, o número de Superintendências Estaduais que adotaram projetos específicos para fiscalização no setor do TRC pareceu insuficiente diante da gravidade dos indicadores do setor. Na maior parte dos estados, as fiscalizações no setor do TRC no período deste estudo ficaram inseridas dentro de projetos chamados "Outras demandas", que incluem as CNAE não contempladas em projetos específicos, estes sim definidos como prioritários e que preveem estratégias para $\mathrm{o}$ atendimento das demandas. $\mathrm{O}$ número de estados com projetos específicos de TRC caiu de sete, em 2010, para quatro, em 2011 e 2012. O estado de São Paulo, pelo qual trafega grande parte da carga rodoviária do país, possuía um projeto específico de fiscalização do TRC em 2010 e deixou de tê-lo em 2011 e 2012.

O critério de proporcionalidade entre ATFs e número de fiscalizações não é o único a ser observado no planejamento da fiscalização. No entanto, esse critério deve ser tomado como um dos principais, haja vista a atividade profissional em estudo ser a mais atingida no que concerne à vida humana. Além disso, as causas identificadas na literatura como contribuintes para as mortes devem ser primordialmente consideradas, implicando, destarte, a verificação das condições das jornadas e do descanso dos motoristas.

Quanto às limitações deste estudo, é importante ressaltar que os dados da RAIS, assim como os de ATFs utilizados, tanto os extraídos dos Anuários Estatísticos, quanto os fornecidos pelo Ministério da Previdência Social à SIT, referem-se apenas aos vínculos formais, desconhecendo-se os dados especificamente relacionados aos motoristas autônomos e, sobretudo, aos informais, onde provavelmente, todas as condições aqui discutidas são ainda mais graves. Também é preciso considerar que os dados de ATFs são baseados nas Comunicações de Acidentes de Trabalho (CAT), que, via de regra, são emitidas pelos próprios empregadores.
Eventualmente, o acidente pode não ser notificado pelo empregador. Um dos motivos possíveis para essa atitude é que o aumento no número de AT numa determinada atividade econômica pode aumentar o custo previdenciário das empresas que exploram essa atividade. Embora o INSS alegue ter resolvido o problema da subnotificação de AT com a implantação do Nexo Técnico Epidemiológico Previdenciário (NTEP) a partir de $2007^{36}$, quando o próprio INSS passou a classificar o benefício como acidentário ou previdenciário independentemente da emissão da CAT, não há evidências mostrando que a questão da subnotificação tenha sido resolvida.

\section{Conclusão}

Considerando que o quantitativo de acidentes fatais e a taxa de mortalidade por acidentes de trabalho são critérios relevantes a serem considerados no planejamento de ações de fiscalização, verificou-se que o setor do TRC não foi devidamente contemplado nas inspeções realizadas no período analisado. A forma como a Fiscalização do Trabalho se organizou e atuou frente ao setor não contemplou a gravidade dos indicadores de ATF no TRC quanto ao número de fiscalizações, ao número de acidentes de trabalho analisados e nem quanto à inspeção dos atributos "Jornada” e "Descanso", fatores considerados relevantes nas pesquisas científicas como predisponentes aos acidentes de trabalho.

O planejamento das ações fiscais não se mostrou coerente com o diagnóstico e nem a execução contemplou a verificação dos fatores mais relevantes em relação aos riscos de acidentes de trabalho. Torna-se necessário que a Fiscalização do Trabalho considere esses aspectos, num cenário em que, cada vez mais, os recursos se tornam escassos e a priorização se torna indispensável.

\section{Contribuição de autoria}

Fragoso Junior A concebeu o projeto e realizou o levantamento e a análise dos dados. Garcia EG orientou o projeto e participou da análise dos dados. Ambos participaram da elaboração e aprovação da versão final do manuscrito publicado.

\section{Referências}

1. Confederação Nacional dos Transportes. Boletim Estatístico CNT - maio/2013 [Internet]. 2013 [acesso em 16 jul 2013]. Disponível em: http://www.cnt.org. br/Boletim/boletim-estatistico-cnt.

2. Brasil. Ministério do Trabalho e Emprego. Programa de Disseminação de Estatísticas do Trabalho. Relação Anual de Informações Sociais. Empregos em 31/12/2012 [Internet]. 2014 [acesso em 20 mai 2014]. Disponível em: http://bi.mte.gov.br/bgcaged/ caged_anuario_rais/caged_anuario_raistela17.php.

3. Brasil. RNTRC em números. Transportadores maio/2014 [Internet]. 2014 [acesso em 21 mai 2014]. Disponível em: http://www.antt.gov.br/ cargas/arquivos_old/Estatisticas.html. 
4. Instituto de Pesquisa Econômica Aplicada. Acidentes de Trânsito nas Rodovias Federais Brasileiras - Caracterização, Tendências e Custos para a Sociedade. IPEA; 2015.

5. Santana V, Moura MCP, Pedra F, Corrêa H, Venâncio J, Belino L. Morbimortalidade por acidentes de trabalho em motoristas do transporte de carga, 2006-2012. Boletim Epidemiológico Acidentes de Trabalho. 2013; 3(6):1-4.

6. Dawson D, Fletcher A, Hussey F. Beyond the midnight oil: Parliamentary enquiry into managing fatigue in transport. Adelaide Centre for Sleep Research, University of South Australia. 2000.

7. Moreno CR de C, Rotenberg L. Fatores determinantes da atividade dos motoristas de caminhão e repercussões à saúde: um olhar a partir da análise coletiva do trabalho. Rev Bras Saude Ocup [Internet]. 2009 Dez [citado 2019 Fev 13]; 34(120): 128-138. Disponível em: http://dx.doi. org/10.1590/S0303-76572009000200004.

8. Goudswaard A, Kuipers B, Schoenmaker N, Houtman IL, Jettinghof K, Ruijs P, et al. Road Transport Working Time Directive, Self-employed and Night Time Provisions. The Netherlands: Netherlands Organisation for Applied Scientific Research; 2006.

9. European Transport Safety Council. The role of drive fatigue in commercial road transport crashes. Brussels: European Transport Safety Council; 2001.

10. Beaulieu JK. The issues of fatigue and working time in the road transport sector. Geneva: International Labour Organization; 2005.

11. Arnedt JT, Wilde GJ, Munt PW, MacLean AW. How do prolonged wakefulness and alcohol compare in the decrements they produce on a simulated driving task? Accident Analysis and Prevention. 2001;33(3):337-44.

12. Lamond N, Dawson D. Quantifying the performance impairment associated with fatigue. Journal of sleep research. 1999;8(4):255-62.

13. Ulhôa MA, Marqueze EC, Lemos LC, Silva LG da, Silva AA, Nehme P, et al. Minor psychiatric disorders and working conditions in truck drivers. Revista de Saúde Pública. 2010;44(6):1130-6.

14. Pinho RSN, da Silva-Junior FP, Bastos JPC, Maia WS, de Mello MT, de Bruin VMS, et al. Hypersomnolence and accidents in truck drivers: a cross-sectional study. Chronobiology International. 2006;23(5):963-71.

15. Silva LG da. O trabalho dos motoristas de caminhão: a relação entre atividade, vínculo empregatício e acidentes de trabalho [dissertação]. São Paulo: Universidade de São Paulo; 2011.

16. Brasil. Fundação Instituto Brasileiro de Geografia e Estatística. Comissão Nacional de Classificação. Resolução $\mathrm{n}^{\mathrm{o}}$ 1, de 4 de setembro de 2006. 2006.

17. Brasil. Ministério do Trabalho e Emprego. Ministério da Previdência Social. Anuário
Estatístico de Acidentes do Trabalho: AEAT 2010. Brasília; 2011

18. Brasil. Ministério do Trabalho e Previdência Social. Anuário Estatístico de Acidentes do Trabalho: AEAT 2013. Brasília; 2013.

19. Brasil. Ministério do Trabalho e Emprego. Portaria $\mathrm{n}^{\circ} 397$, de 9 de outubro de 2002. Aprova a Classificação Brasileira de Ocupações - CBO/2002, para uso em todo território nacional e autoriza a sua publicação. 2002.

20. Brasil. Decreto ${ }^{\circ} 3.048$ de 6 de maio de 1999. Aprova o Regulamento da Previdência Social e dá outras providências. 1999.

21. Brasil. Ministério do Trabalho e Emprego, Ministério da Previdência Social. Acordo de Cooperação Técnica ${ }^{\circ}$ 08/2008, objetivando o estabelecimento de cooperação com vistas à prevenção e repressão de acidentes do trabalho, inclusive ao incremento das ações regressivas de que trata 0 art. 120 da Lei $\mathrm{n}^{\circ} 8.213$, de 24 de julho de 1991. 2008

22. Brasil. Ministério do Trabalho e Emprego. Ministério da Previdência Social. Anuário Estatístico de Acidentes do Trabalho: AEAT 2008. Brasília; 2009.

23. Brasil. Ministério do Trabalho e Emprego. Ministério da Previdência Social. Anuário Estatístico de Acidentes do Trabalho: AEAT 2012. Brasília; 2012.

24. Vianna CSV. Manual Prático das Relações Trabalhistas. 10. ed. São Paulo, SP: LTr; 2009.

25. Brasil. Ministério do Trabalho e Emprego. Portaria $n^{\circ}$ 546, de 11 de março de 2010. Disciplina a forma de atuação da Inspeção do Trabalho, a elaboração do planejamento da fiscalização, a avaliação de desempenho funcional dos Auditores Fiscais do Trabalho, e dá outras providências. Diário Oficial da União, Brasília, DF, 12 mar. 2010. Seção 1, p. 99; 2010.

26. Brasil. Ministério do Trabalho e Emprego. Secretaria de Inspeção do Trabalho. Portaria $\mathrm{n}^{\mathrm{o}}$ 3.214 de 8 de junho de 1978. Aprova as Normas Regulamentadoras - NR - do Capítulo V, Título II, da Consolidação das Leis do Trabalho, relativas a Segurança e Medicina do Trabalho. 1978.

27. Baumecker IC, Khouri M de A, Forte V de J. Guia de Análise Acidentes de Trabalho. Brasília: Ministério do Trabalho. Secretaria de Inspeção do Trabalho; 2010.

28. Mangas RM do N, Gómez CM, da Fonseca ThedimCosta SM. Acidentes de trabalho fatais e desproteção social na indústria da construção civil do Rio de Janeiro. Rev Bras Saude Ocup [Internet]. 2008 Dez [citado 2019 Fev 13]; 33(118): 48-55. Disponível em: http://dx.doi.org/10.1590/S0303-76572008000200006.

29. Fragoso A. A atuação da fiscalização do trabalho no Brasil frente às peculiaridades da organização do transporte rodoviário de carga [dissertação]. São Paulo: Fundação Jorge Duprat Figueiredo de Segurança e Medicina do Trabalho; 2013. 
30. International Center for Alcohol Policies. Blood Alcohol Concentration (BAC) Limits Worldwide [internet]. 2014 [cited 2014 Jun 11]. Available from: http://citeseerx.ist.psu.edu/viewdoc/downloa $\mathrm{d}$ ?doi $=10.1 .1 .695 .439 \& \mathrm{rep}=$ rep1\&type $=$ pdf.

31. Brasil. Lei n ${ }^{\circ} 9.503$ de 23 de setembro de 1997. Institui o Código de Trânsito Brasileiro. 1997.

32. Brasil. Lei no 12.619, de 30 de abril de 2012. Dispõe sobre o exercício da profissão de motorista. [internet]. 2012 [acesso em 12 out 2017]. Disponível em: http://www.planalto.gov.br/ ccivil_03/_ato2011-2014/2012/lei/l12619.htm.

33. Brasil. Lei $\mathrm{n}^{\mathrm{o}}$ 13.103, de 2 de março de 2015. Dispõe sobre o exercício da profissão de motorista. [internet]. 2015 [acesso em 12 out 2017]. Disponível em: http://www.planalto.gov.br/ccivil_03/_ato20152018/2015/lei/l13103.htm.

34. Piore MJ, Schrank A. Toward managed flexibility: The revival of labour inspection in the Latin world. International Labour Review. 2008;147(1):1-23.

35. Cardoso A, Lage T. A inspeção do trabalho no Brasil. Revista de Ciências Sociais. 2005;48(3):451-90.

36. Pereira E da S. Ministério da Previdência Social: fontes de informação para a saúde e segurança do trabalhador no Brasil. In: Chagas AMR, Salim CA, Servo LMS, organizadores. Saúde e segurança no trabalho no Brasil: aspectos institucionais, sistemas de informação e indicadores. Brasília: IPEA; 2011. p. 201-31. 